\title{
Evaluation of the Quality Control and Quality Assurance in Mammography mobile Unit
}

\section{Mohamed Saad Zanaty ${ }^{1}$, Tarek Mohamed El-Desoky ${ }^{2}$, Hanan Mohamed Diab ${ }^{3}$, Kassem Abdelhalem Mostafa ${ }^{1}$}

${ }^{1}$ Executive Office for Radiation Protection, Cairo, Egypt

${ }^{2}$ Faculty of Women for Arts, Sci., and Education, Ain Shams University, Cairo Egypt

${ }^{3}$ Nuclear and Radiological Regulatory Authority, Cairo, Egypt

\begin{abstract}
The aim of this study was to undertake a comprehensive evaluation of selected mammography unit. The materials used mammography machine Philips, multi-electrometer, target and filter combinations $\mathrm{W} / \mathrm{Rh}, \mathrm{Mo} / \mathrm{Rh}$ and $\mathrm{Mo} / \mathrm{Mo}$ and Aluminum layers. The quality control assessment was performed on the selected machine. The assessment was done included $\mathrm{kV}$ accuracy and reproducibility and Half Value Layer measurement. The results obtained confirmed that the machine is working correctly and was within acceptable performance criteria. The results of the physical parameters indicated a deviation of tube potential for the examined tube from the nominal values with the standard deviation $( \pm 5 \%)$, except the few values exceeds this levels, and the conclusion is that some adjustments showed be done and the have value layer at the nominal tube potential $(28 \mathrm{kV})$ was in agreement with the published values.
\end{abstract}

Key words: Mammography, QC/QA, accuracy and reproducibility, HVL, kilovoltage, machine current.

\section{Introduction}

Breast screening depends on diagnostic procedure to discover cancer in its early stages thanks to little changes in tissue composition. Like any examination that features x-rays, there's invariably little random risk of causing cancer. It's so necessary to judge the danger from the dose delivered to the patient throughout the screening method, in alternative words, to stay the dose as low as moderately accomplishable (Dance et al., 2000). Mammography needs prime quality standers since the distinction between traditional and pathological areas within the breast is extraordinarily low.

X-ray examinations remain the foremost oftentimes used radiation in medication, constituting the foremost important simulated supply of radiation exposure for the planet population. However, the increasing use of x-ray in hospitals has created a very important source of radiation within the population collective dose. In diagnostic radiology, periodic dose assessments ought to be created to encourage the improvement of the radiation protection of the patients. Dose measurements are needed any to check completely different imaging techniques and to go with some international tips and rules (Suliman et al., 2007). Mammography needs a highest image quality for all procedures whereas keeping the radiation dose delivered to the breast, as low as attainable. This can be solely doable by mistreatment optimum instrumentality 
and safe procedures. Also, like any medical checkup managing radiation, there's continually at any low risk of random impact inducement cancer. Therefore, it's important to make sure that the diagnostic procedure units used is functioning accurately and also the radiation dose delivered to the breast and ascertain whether or not it falls at intervals international references levels, (Marianne \& Bengt, 2008).

QA programs as recommended by AAPM and AERB should be carried out periodically to ensure safety in breast cancer screening. This work points to the importance of the regulation and effective compliance and also help in both improving the QA and reduce the glandular dose received by the patients (Selvan and Sureka 2017). Digital imaging allows automation of the image quality analysis, which can potentially improve repeatability and objectivity compared to a visual evaluation made by the users. To develop an automatic image quality analysis software for daily mammography quality control in a multi-unit imaging center (Sundell et al., 2019).

\section{Materials and Methods}

\subsection{Materials}

The materials used for this study are one selected mammography mobile units were Philips, Aluminum layers and $\mathrm{kV}$ and current and effective dose dosimeter.
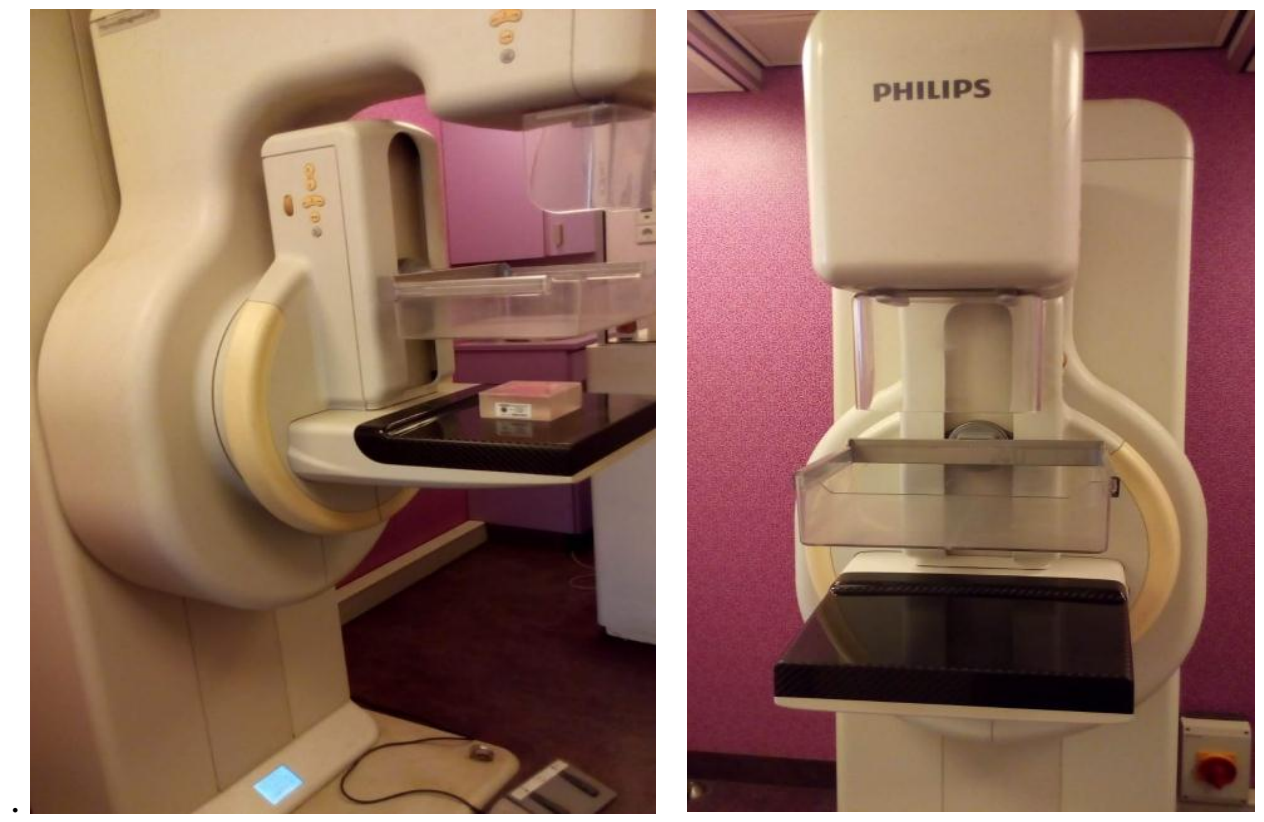

Figure (2.1): Mammography equipment, Philips

The dosimeter used for measurement in this study was the calibrated multi-electrometer. Manufactured by RTI electronics AB, it was used to measure the voltage in $\mathrm{kV}$, current in $\mathrm{mAs}$, Exposure in $\mathrm{mR}$, exposure time measurements in seconds. Multi-electrometer or dosimeter is shown in figure (2.2). 

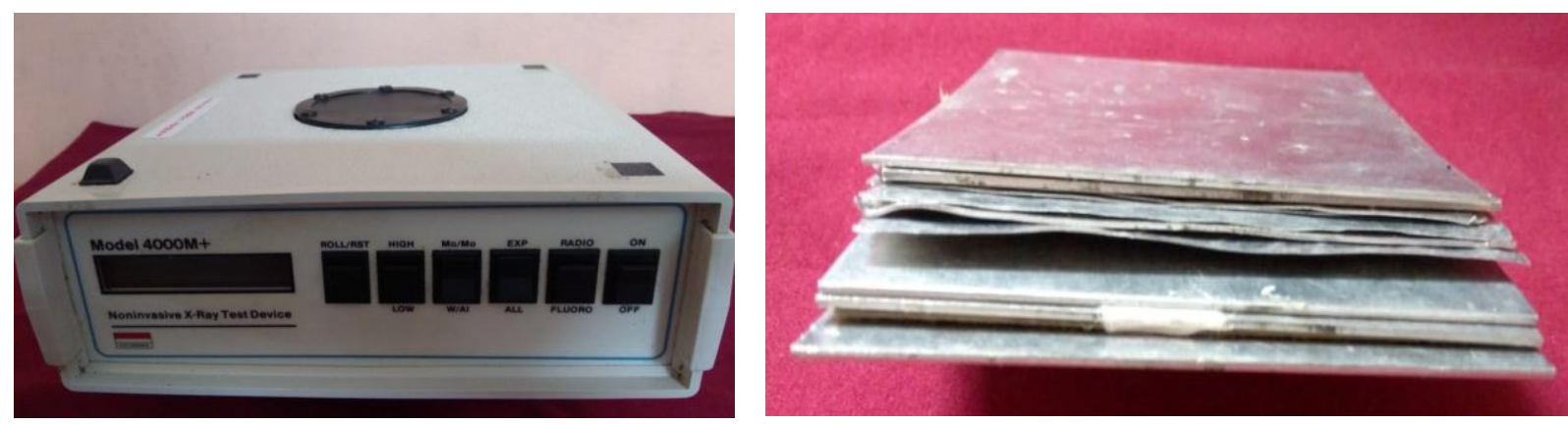

Figure (2.2): Multi-electrometer Model4000M. Figure (2.3): Thin layers of Aluminum filters

We used number of Target and filter combinations such as W/Rh, Mo/Rh, Mo/Mo, and Rh/Rh built-in mammograms and we used number of Aluminum sheets to measure the effective Half Value Layer (HVL) materials shown in figure (2.3).

\subsection{Methods}

QC tests were carried out on the mammography systems to verify whether they were performing with internationally accepted criteria. The QC tests performed included: tube voltage $\mathrm{kV}$ accuracy and reproducibility, HVL, image quality tests and compression.

\subsubsection{Quality Control Tests}

Quality control (QC) tests are carried out to evaluate the performance level radiographic systems in order to ensure that users are provided with best achievable image quality while keeping patient doses as law as reasonably achievable.

The following QC tests were performed for both patient dose measurements and clinical image quality evaluation had been carried out; Reproducibility and accuracy of $\mathrm{kV}$ and HVL determination.

\section{a) Kilovoltage $\mathrm{kV}$ measurement}

Image quality and patient dose are dependent on any variation in the generator kilo voltage $(\mathrm{kV})$ of the X-ray set. Therefore an accurate $\mathrm{kV}$ calibration is required (IAEA, 2009).

Methods of KV accuracy and reproducibility measurement:

- Select number of $\mathrm{kV}$ settings commonly used in the clinical practice range from 25 to $32 \mathrm{kV}$.

- Position the measuring instrument ( $\mathrm{kV}$ meter) on the breast support table.

- Set the mammography unit in the manual mode and carry out three exposures at each $\mathrm{kV}$ to four types of target filter combination at tube current (50/100 mAs) according to mammography unit selected.

- Carry out a single exposure for the other $\mathrm{kV}$ setting selecting and note the values measured on the data to determine the $\mathrm{kV}$ accuracy, calculate the percentage deviation between the nominal value and the measured $\mathrm{kV}$ value for each selected $\mathrm{kV}$. 


\section{Deviation \% $=100$ (kVnom. - kVmeas.) / kVnom.}

Limiting value of accuracy: $\pm 5 \%$

To determine the $\mathrm{kV}$ reproducibility, calculate the measurement percentage difference using the following formula:

\section{Reproducibility $=100$ (Max. reading - Min. reading $) /$ Min. reading}

Limiting value of reproducibility: diff. $\leq 5 \%$

\section{b) Half value layer determination}

The half value was measured to all three target / filter combination for all $\mathrm{x}$-ray units under investigation. Since the estimation of accurate dose required an assessment of half value (IAEA, 2009). The Half Vague Layer (HVL) can be assessed by adding thin aluminum (Al) filters to the $\mathrm{X}$-ray beam and measuring the attenuation.

- Position the exposure detector on top of the bucky.

- Place the compression multi electrometer on top of the bucky.

- Place the compression device have way between focal spot and detector.

- Select $28 \mathrm{kV}$ tube voltage and an adequate focal spot charge (mAs-setting) and expose the detector directly.

- The filters can be positioned on the compression device and must intercept the hole radiation field.

- Use the same mAs setting and expose the detector through each filter.

- Note limiting value for $28 \mathrm{kV}$ Mo/Mo the HVL must be over $0.3 \mathrm{mmAl}$ equivalent.

\section{Results and Discussion}

Quality assurance applied to the radio diagnostic practice is intrinsically related to medical ethics. It's primary is goal to guarantee the fulfillment of three basic criteria: a) Be necessary and appropriate to solve the clinical problem; b) Be able to produce images with enough information to solve the clinical problem; and c) Be optimized, in order that the screening or diagnostic examination results in the lowest possible radiation exposure, lower costs, and inconvenience to the patient. Results for equipment testing, presented in Table I, shows correspondence with adopted tolerances for most quality control tests, except for irradiation geometry and AEC tests. Radiation from routine mammography poses significant cumulative risk of initiating and promoting breast cancer (Suliman et al., 2007, Modupe et al., 1999, Olivera et al., 2005,).

Contrary to conventional assurances that radiation exposure from mammography is trivial--and similar to that from a chest X-ray or spending one week in Denver, about 1/1,000 of a rad (radiation-absorbed dose)--the routine practice of taking four films for each breast results in some 1,000-fold greater exposure, $1 \mathrm{rad}$, focused on each breast rather than the entire chest (Olivera et al., 2005). Thus, premenopausal women undergoing annual screening over a ten-year period are exposed to a total of about 10 rads for each breast. As emphasized some three decades 
ago, the premenopausal breast is highly sensitive to radiation, each rad of exposure increasing breast cancer risk by 1 percent, resulting in a cumulative 10 percent increased risk over ten years of premenopausal screening, usually from ages 40 to 50 (4); risks are even greater for «baseline» screening at younger ages, for which there is no evidence of any future relevance.

\subsection{Quality Control Tests}

Quality Control (QC) tests are carried out to evaluate the performance level of radiographic systems in order to ensure that users are provided with the best achievable image quality while keeping patient doses as low as reasonably achievable. The following QC tests were performed of clinical image quality evaluation had been carried out; Accuracy and Reproducibility of kV and HVL determination. The quality control tests methods used, as well as the criteria for scoring the results, were in full agreement with those specified in the European Protocol for the Quality Control of the Physical and Technical Aspects of Mammography Screening.

\subsubsection{Tube voltage accuracy and reproducibility}

The reproducibility and accuracy of the tube voltage are essential in mammography. They guarantee a constant quality of image when repeating the exposure at same settings. This allows the practitioner to precisely select the appropriate $\mathrm{kV}$ value for the examination. The tube voltage (KV) used during medical examination in mammography fall within the range (25-32 kV); thus this range were studied using calibrated test device and the $\mathrm{kV}$ values for each nominal tube voltage are measured. The relation between the nominal and the measured values of tube voltage are represented in table (3.1) and as shown in figure (3.4) for the mobile unit. From this figure it is clear that the measured tube voltage has an acceptable deviation from the nominal values table. The results of $\mathrm{KV}$ accuracy and reproducibility of Philips mobile unit for all target filter combinations were as shown in tables $(3.4$ - 3.6).

Table (3.1): Values of nominal $\mathrm{kV}$ and measured $\mathrm{kV}$ for mobile unit with $100 \mathrm{mAs}$ and $\mathrm{W} / \mathrm{Rh}$

\begin{tabular}{|c|c|}
\hline $\begin{array}{c}\text { Nominal } \\
\mathbf{k V}\end{array}$ & $\begin{array}{c}\text { Measured } \\
\mathbf{k V}\end{array}$ \\
\hline 25 & 27.72 \\
\hline 26 & 28.08 \\
\hline 27 & 28.28 \\
\hline 28 & 28.75 \\
\hline 29 & 29.34 \\
\hline 30 & 30.02 \\
\hline 31 & 30.9 \\
\hline 32 & 31.95 \\
\hline
\end{tabular}




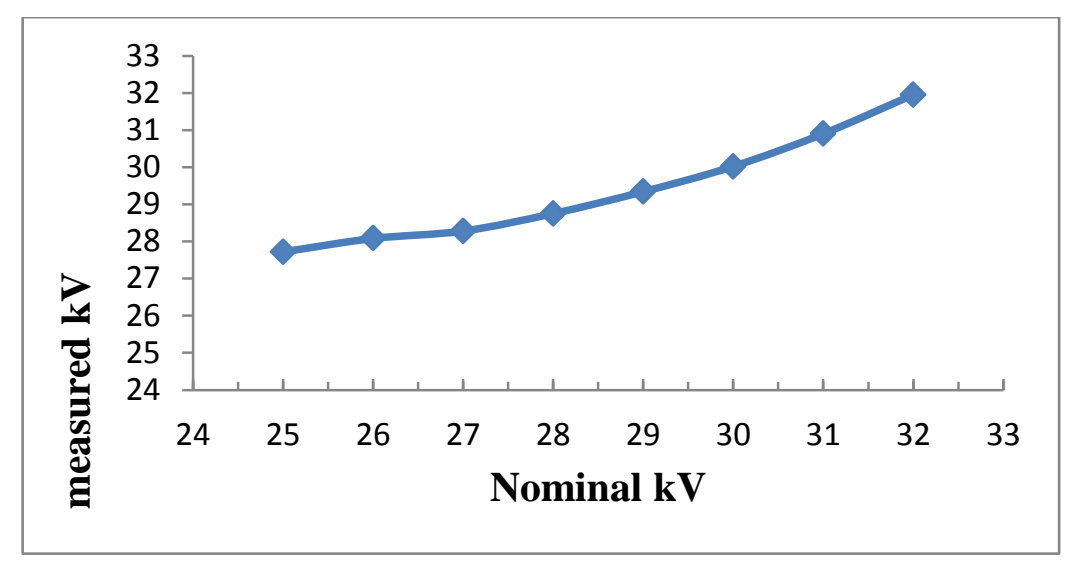

Figure (3.1): Values of nominal kV and measured $\mathrm{kV}$ for mobile unit Philips with $100 \mathrm{mAs}$ and target filter combination $\mathrm{W} / \mathrm{Rh}$.

Table (3.2): Values of nominal $\mathrm{kV}$ and measured $\mathrm{kV}$ for mobile unit Philips with Pre-set tube load $100 \mathrm{mAs}$ and target filter combination $\mathrm{Mo} / \mathrm{Rh}$

\begin{tabular}{|c|l|}
\hline $\begin{array}{c}\text { Nominal } \\
\mathbf{k V}\end{array}$ & $\begin{array}{c}\text { Measured } \\
\mathbf{k V}\end{array}$ \\
\hline 25 & 26.8 \\
\hline 26 & 27.1 \\
\hline 27 & 27.77 \\
\hline 28 & 28.51 \\
\hline 29 & 29.29 \\
\hline 30 & 30.1 \\
\hline 31 & 31.08 \\
\hline 32 & 31.94 \\
\hline
\end{tabular}

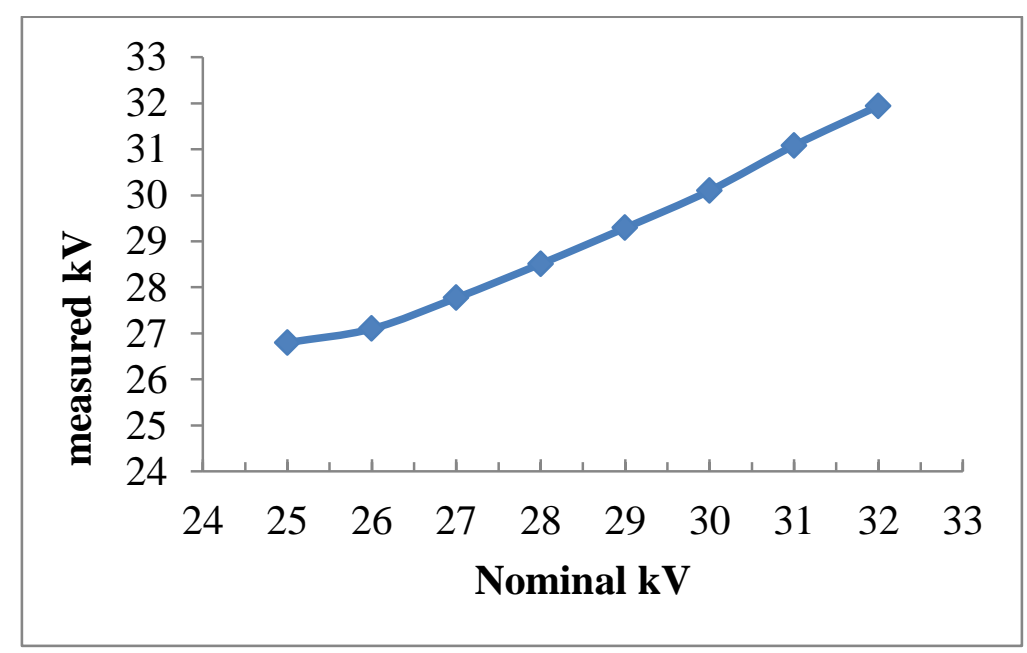

Figure (3.2): Values of nominal $\mathrm{kV}$ and measured $\mathrm{kV}$ for mobile unit Philips with Pre-set tube load $100 \mathrm{mAs}$ and target filter combination $\mathrm{Mo} / \mathrm{Rh}$ 
Table (3.3): Values of nominal $\mathrm{kV}$ and measured $\mathrm{kV}$ for mobile unit Philips with Pre-set tube load $100 \mathrm{mAs}$ and target filter combination Mo/Mo

\begin{tabular}{|c|l|}
\hline $\begin{array}{c}\text { Nominal } \\
\mathbf{k V}\end{array}$ & $\begin{array}{c}\text { Measured } \\
\mathbf{k V}\end{array}$ \\
\hline 25 & 27.46 \\
\hline 26 & 27.84 \\
\hline 27 & 28.13 \\
\hline 28 & 28.74 \\
\hline 29 & 29.04 \\
\hline 30 & 29.74 \\
\hline 31 & 30.61 \\
\hline 32 & 31.55 \\
\hline
\end{tabular}

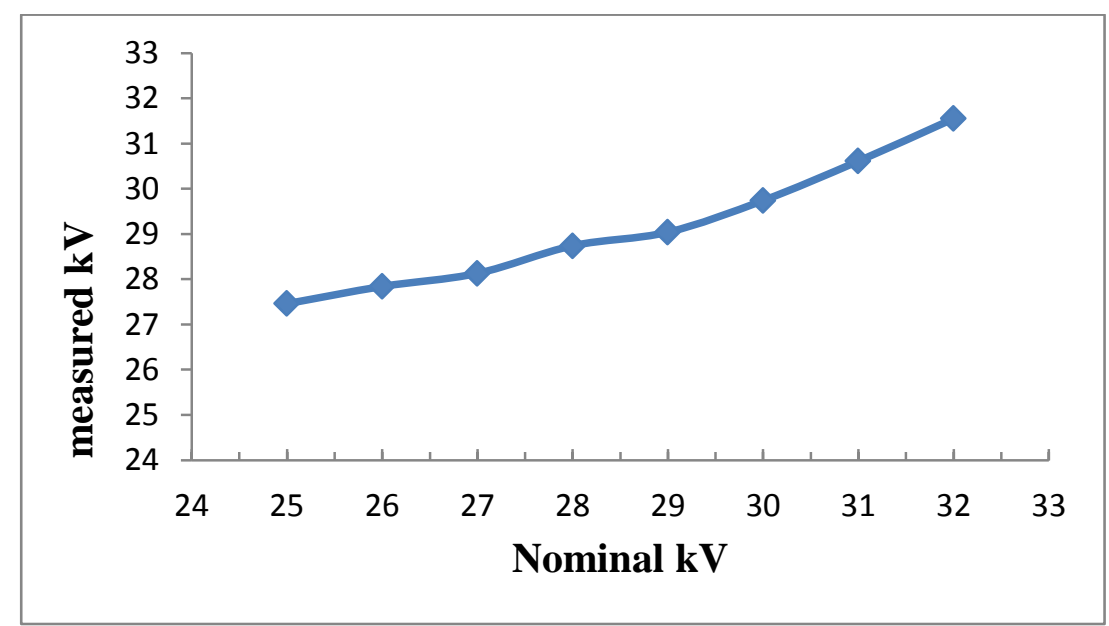

Figure (3.3): Values of nominal $\mathrm{kV}$ and measured $\mathrm{kV}$ for mobile unit Philips with Pre-set tube load $100 \mathrm{mAs}$ and target filter combination $\mathrm{Mo} / \mathrm{Mo}$

Table (3.4): Values of nominal $\mathrm{kV}$ and measured $\mathrm{kV}$ for mobile unit Philips with Pre-set tube load $100 \mathrm{mAs}$ for W/Rh Target filter combination

\begin{tabular}{|l|l|l|l|l|l|l|l|l|}
\hline Nom. KV & 25 & 26 & 27 & 28 & 29 & 30 & 31 & 32 \\
\hline Measured & 27.33 & 27.74 & 28.0 & 28.49 & 29.1 & 29.81 & 30.76 & 31.77 \\
\hline Deviation \% & -9.32 & -6.44 & -3.7 & -1.75 & -0.3 & 0.63 & 0.77 & 0.72 \\
\hline Reproducibility & 0.01 & 0.01 & 0.01 & 0.003 & 0.001 & 0.01 & 0.002 & 0.002 \\
\hline
\end{tabular}

Table (3.5): Values of nominal $\mathrm{kV}$ and measured $\mathrm{kV}$ for mobile unit Philips with Pre-set tube load $100 \mathrm{mAs}$ for $\mathrm{Mo} / \mathrm{Rh}$ Target filter combination

\begin{tabular}{|l|l|l|l|l|l|l|l|l|}
\hline Nom. KV & 25 & 26 & 27 & 28 & 29 & 30 & 31 & 32 \\
\hline Measured & 26.15 & 26.64 & 27.39 & 27.91 & 29.38 & 29.89 & 30.89 & 31.81 \\
\hline Deviation \% & -4.6 & -2.46 & -1.44 & 0.32 & -1.31 & 0.37 & 0.35 & 0.59 \\
\hline Reproducibility & 0.01 & 0.002 & 0.02 & 0.002 & 0.04 & 0.001 & 0.001 & 0.001 \\
\hline
\end{tabular}


Table (3.6): Values of nominal $\mathrm{kV}$ and measured $\mathrm{kV}$ for mobile unit Philips with Pre-set tube load $100 \mathrm{mAs}$ for Mo/Mo Target filter combination

\begin{tabular}{|l|l|l|l|l|l|l|l|l|}
\hline Nom. kV & 25 & 26 & 27 & 28 & 29 & 30 & 31 & 32 \\
\hline Measured & 27.0 & 27.54 & 27.78 & 28.1 & 28.78 & 29.52 & 30.37 & 31.38 \\
\hline Deviation \% & -8 & -5.92 & -2.9 & -0.36 & 0.76 & 1.6 & 2.03 & 1.9 \\
\hline Reproducibility & 0.01 & 0.01 & 0.001 & 0.003 & 0.005 & 0.004 & 0.003 & 0.001 \\
\hline
\end{tabular}

As for the accuracy of the tube voltage, deviations greater than $\pm 5 \%$ over the range of the available $\mathrm{kV}$ of the machine $25 \mathrm{kV}$ and $26 \mathrm{kV}$ for $\mathrm{W} / \mathrm{Rh}$ and Mo/Mo target filter combination are to be considered as an unacceptable and need to be fixed. The results of KV accuracy for target filter combination showed that deviations were less than $\pm 5 \%$ over the range of the available KV sets $(27-32 \mathrm{kV})$ of the machine are to be considered as acceptable values. The results of $\mathrm{KV}$ reproducibility indicated that, the difference percentage were less than 5\%for the range of $\mathrm{KV}$ nominal and this indicates that the unit is in good work condition. The results of KV accuracy and reproducibility of the unit for all target filter combinations were shown in tables (3.4-3.6). The results of $\mathrm{KV}$ accuracy for $\mathrm{Mo} / \mathrm{Rh}$ combination showed that deviations were less than $\pm 5 \%$ over the whole range of the available $\mathrm{KV}$ sets of the machine are to be considered as acceptable values. The results of KV reproducibility indicate that, the difference percentage were less than $\pm 5 \%$ for the range of $\mathrm{KV}$ setting $(25 \mathrm{kV}-32 \mathrm{kV})$.

For W/Rh target filter combination, the data showed that, greater deviation than the recommended limiting values at certain tube voltage at 25 and $26 \mathrm{KV}$, the deviation were $-9.32 \%$ and $-6.44 \%$ respectively. These deviations percentage indicate that there is a problem in this unit for this target filter combination and need to be readjusted as shown in table (3.4).

The results of KV accuracy for Mo/Rh combination showed that deviations were less than $\pm 5 \%$ over the whole range of the available $\mathrm{KV}$ sets of the machine are to be considered as acceptable values as shown in table (3.5) and the results of KV reproducibility indicate that, the difference percentage were less than $5 \%$ for the range of $\mathrm{KV}$ nominal which indicates that the unit is in good work condition.

For Mo/Mo target filter combination the data showed that, greater deviation than the recommended limiting values at certain tube voltage, at 25 and $26 \mathrm{KV}$, the deviation were $-8.0 \%$ and $-5.92 \%$ respectively. These deviations percentage indicate that there is a problem in this unit for Mo/Mo target filter combination and need to be readjusted as shown in table (3.6).

\subsubsection{Half value layer (HVL)}

In diagnostic $\mathrm{x}$-ray tubes, the half value layer (HVL) plays an important role to qualify the beam and unnecessary radiation exposure. In this study, the half value layer (HVL) was evaluated in the kilovoltage range of interest for Philips mobile unit by adding thin aluminum filters to the 
$\mathrm{X}$ ray beam and measuring the transmission (attenuation) in 'good geometry' i.e. for narrow beam conditions to minimize the influence of scattered radiation and it was calculated

Table (3.7): Variation of the thickness of $\mathrm{Al}$ filter with the exposure ( $\mathrm{mR}$ ) of mobile unit, for clinically most relevant $28 \mathrm{KV}$ with $100 \mathrm{mAs}$ and W/Rh target filter combination

\begin{tabular}{|l|l|l|l|l|l|l|l|}
\hline $\begin{array}{l}\text { Al Thickness } \\
\text { in mm. }\end{array}$ & 0.0 & 0.1 & 0.2 & 0.3 & 0.4 & 0.5 & 0.6 \\
\hline Exposure (mR) & 425.5 & 368.7 & 320.9 & 280.7 & 246.8 & 218.0 & 192.9 \\
\hline Transmission \% & 100 & 86.7 & 75.4 & 65.9 & 58.0 & 51.2 & 45.3 \\
\hline
\end{tabular}

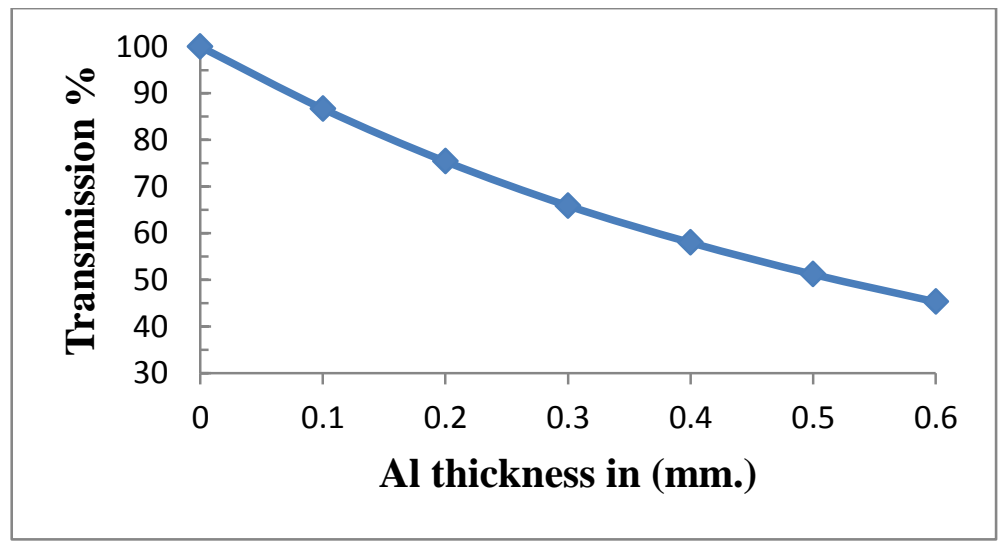

Figure (3.4): Variation of the thickness of Al filter with the exposure (mR) of mobile unit, for clinically most relevant $28 \mathrm{KV}$ with $100 \mathrm{mAs}$ and W/Rh target filter combination

Table (3.8): Variation of the thickness of Al filter with the exposure (mR) of mobile unit, for clinically most relevant $28 \mathrm{KV}$ with $100 \mathrm{mAs}$ and Mo/Rh target filter combination

\begin{tabular}{|l|l|l|l|l|l|}
\hline $\begin{array}{l}\text { Al Thickness } \\
\text { in mm. }\end{array}$ & 0.0 & 0.1 & 0.2 & 0.3 & 0.4 \\
\hline Exposure $(\mathrm{mR})$ & 1058 & 879.5 & 735.2 & 635.5 & 531.1 \\
\hline Transmission \% & 100 & 83.1 & 69.49 & 60.1 & 50 \\
\hline
\end{tabular}




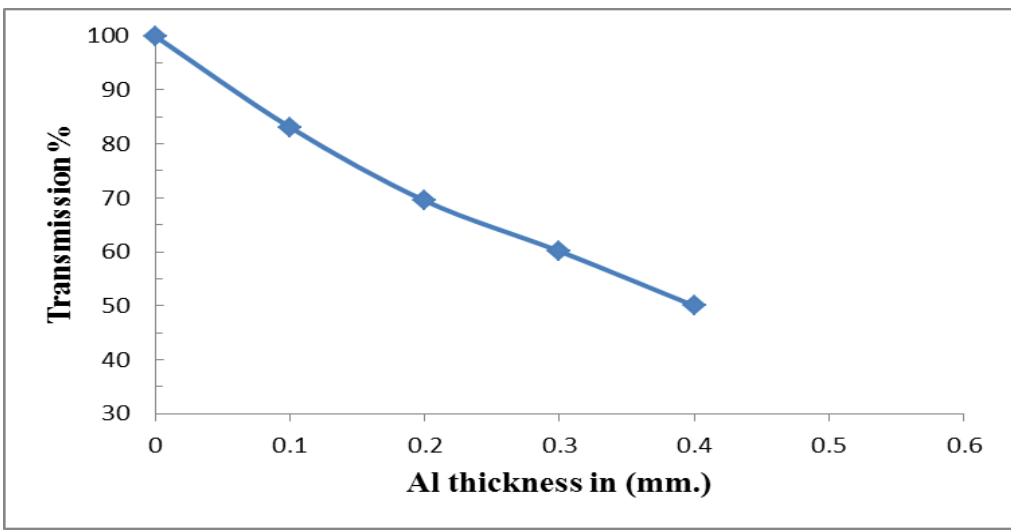

Figure (3.5): Variation of the thickness of $\mathrm{Al}$ filter with the exposure (mR) of mobile unit, for clinically most relevant $28 \mathrm{KV}$ with $100 \mathrm{mAs}$ and $\mathrm{Mo} / \mathrm{Rh}$ target filter combination

Table (3.9): Variation of the thickness of Al filter with the exposure (mR) of mobile unit, for clinically most relevant $28 \mathrm{KV}$ with $100 \mathrm{mAs}$ and Mo/Mo target filter combination

\begin{tabular}{|l|c|c|c|c|c|}
\hline $\begin{array}{l}\text { Al Thickness } \\
\text { in mm. }\end{array}$ & 0.0 & 0.1 & 0.2 & 0.3 & 0.4 \\
\hline Exposure (mR) & 1416.0 & 1133.0 & 921.5 & 761.2 & 635.8 \\
\hline Transmission \% & 100 & 80.0 & 65.0 & 54.0 & 45.0 \\
\hline
\end{tabular}

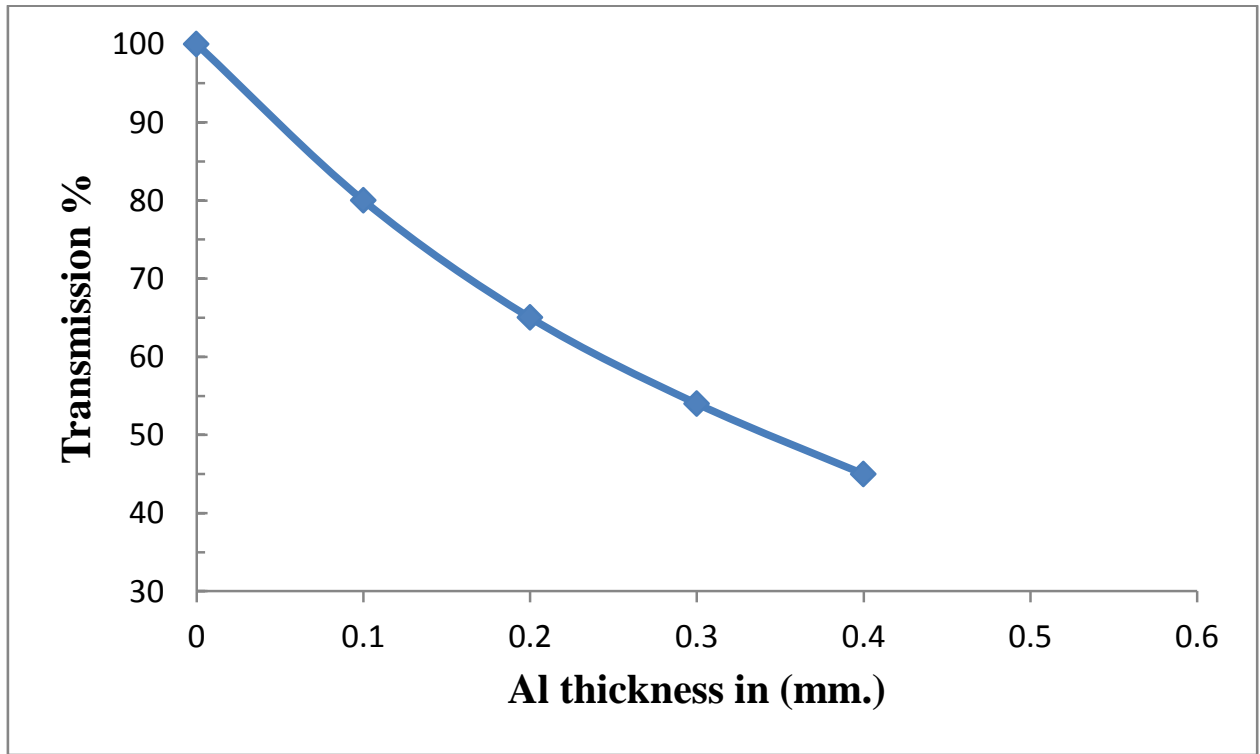

Figure (3.6): Variation of the thickness of Al filter with the exposure (mR) of mobile unit, for clinically most relevant $28 \mathrm{KV}$ with $100 \mathrm{mAs}$ and Mo/Mo target filter combination. 
For the selected mobile unit, HVL was measured for the three target filter combinations and shown in table (3.7). The value of the HVL for W/Rh in this study was in the order of 0.488 and $0.4 \mathrm{~mm} \mathrm{Al}$ for $\mathrm{Mo} / \mathrm{Rh}$ and 0.278 for $\mathrm{Mo} / \mathrm{Mo}$ selected kilovolt $28 \mathrm{kV}$ as shown in tables (3.7 $-3.9)$ and figures (3.4-3.6).

\section{Conclusion}

The quality control assessment was performed on the mammography machine selected. The assessment done included $\mathrm{kV}$ accuracy and reproducibility and Half Value Layer measurement and the results obtained confirmed that the machine is working correctly and were within acceptable performance criteria. The results of the physical parameters indicated a deviation of tube potential $(\mathrm{kV})$ for the examined tube from the nominal values with the standard deviation $( \pm 5 \%)$, except a few values exceeds this levels, indicated that some adjustments showed be done. The Have Value Layer (HVL) at the nominal tube potential $(28 \mathrm{kV})$ was in agreement with the published values.

\section{Reference}

Dance DR., Skinner C.L., Young K. C. Beckett J. R. and Kotre C. J., (2000). Additional factors for the estimation of mean glandular breast dose using the UK mammography dosimetry protocol. Phys. Med. Biol. 45: 3225.

IAEA,(2009). Quality assurance program for screen film mammography: IAEA Human Health Series no. 2, International Atomic Energy Agency, Vienna,.

Marianne, C., \& Bengt, A., (2008). Absorbed Dose Measurement in Mammography.

Oresegun M, LeHeron J, Maccia C, Padovani R, Vano E., (1999). Radiation protection and quality assurance in diaagonstic radioiogy - IAEA coordinated research project in Asia and Eastern Europa, ; applied radiation and isotopes 50: 271- 276.

Olivera Ciraj, Dusko Kosutic, Milojko Kovacevic, and Srpko Markovic, (2005). A survey of patient doses from conventional diagnostic radiology examinations: first results from Serbia and Montenenegro. Physica Medica XXI, N.4: 159.

Senthamil Selvan C, Sureka CS., (2017). Quality assurance and average glandular dose measurement in mammography units. Journal of Medical Physics. Volume 42, Issue 3, Page: $181--190$

Suliman I. I., Abbas N., and Habbani F. I., (2007). Entrance surface doses to patients undergoing selected diagnostic x-ray examinations in Sudan. Radiat. Prot. Dosimetry, 123 (2): 209.

Veli-Matti Sundell, Teemu Ma“kela, Alexander Meaney, Touko Kaasalainen and Sauli Savolainen,(2019). Automated daily quality control analysis for mammography in a multi-unit imaging center Acta Radiologica. Vol. 60(2) 140-148. 


\section{الملخص باللغة العربية}

"تقييم مراقبة الجوده وضمان الجوده فى وحدة تصوير الثذى بالاشعة6،

محمد سعد زناتى (') وطارق محمد الاسوقى(") وحنان محمد دياب(") وقاسم عبدالحليم مصطفى (')

(') المكتب التنفيذي للوقاية من الأشعة - وز ارة الصحة و السكان

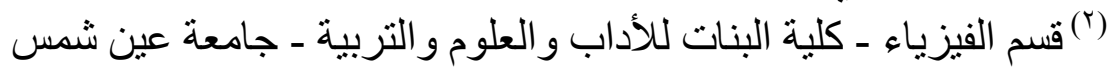

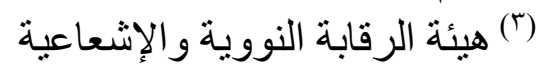

الهذف من هذه الدراسة إجراء تقييم شامل لوحدة مختارة من التصوير الاشعاعي للثذي. المواد

W / المستخدمة آلة التصوير الاشعاعي للثدي فيليبس، الكترومتر متعدد الاغر اض ، ومجموعة المرشحات و و Ro / Mo ، Rh أُجري التقيم بما في ذلك دقة kV وقابلية التكرار وقياس طبقة نصف القيمة. و أكدت النتائج التي تم الحصول عليها أن الجهاز يعمل بشكل صحيح وكان ضمن معايير الأداء المقبولة. وأشارت نتائج العو امل الفيزيائية إلى

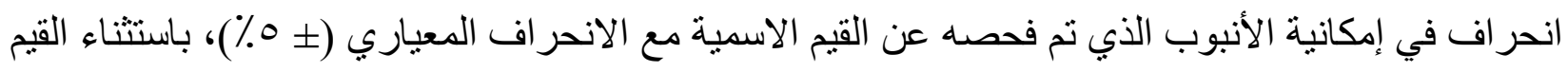
القليلة التي تتجاوز هذه المستويات، والاستتناج هو أنه يجب القيام ببعض التعديلات وأن طبقة نصف القيمة للأنبوب (HVL) 